\title{
Preclinical coronary atherosclerosis in a population with low incidence of myocardial infarction: cross sectional autopsy study
}

\author{
Antonia Bertomeu, Olga García-Vidal, Xavier Farré, Albert Galobart, Manuel Vázquez, \\ Juan Carlos Laguna, Emilio Ros
}

Studies of autopsies indicate that atherosclerosis begins in childhood and is related to risk factors for coronary heart disease in the same way as for adult atherosclerosis. ${ }^{1}$ In Spain, despite risk factors for coronary heart disease being common, incidence of myocardial infarction and related mortality rates are among the lowest in the world. ${ }^{2}{ }^{3}$ This paradox may be explained in two ways. One theory proposes that there is a time lag between increased consumption of animal fat and raised serum cholesterol concentrations, which have occurred more recently in Mediterranean populations than in other Western countries, and the expected increase in rates of coronary heart disease. ${ }^{4}$ An alternative explanation is that Mediterranean countries share behavioural and socioeconomic factors that prevent or delay atherogenesis. ${ }^{5}$ If this is true, the arteries of young Spaniards should be free from atheroma. We studied autopsies to evaluate the prevalence and severity of atherosclerosis in several arterial beds of young trauma victims from Barcelona. We report the results of left coronary artery evaluation.

\section{Participants, methods, and results}

At four forensic laboratories in Barcelona we consecutively collected specimens from 65 young and healthy people (50 men and 15 women) aged $12-35$ years who died of external causes. We measured thiocyanate in postmortem serum by spectrophotometry (an objective measure of smoking), and we determined lipoprotein cholesterol with an enzymatic method. We measured the circumference of the waist and hips, and we analysed subcutaneous abdominal adipose tissue by gas chromatography for fatty acids.

After weighing the heart, we dissected the left coronary artery and stained $3 \mu \mathrm{m}$ transverse sections embedded in paraffin with haematoxylin eosin. We graded the severity of atherosclerotic lesions microscopically using the criteria of the American Heart Association. ${ }^{1}$ We used $\chi^{2}$ tests, Fisher's exact test, or unpaired $t$ tests with a $5 \%$ alpha risk to examine whether atherosclerosis was related to age and if severity of lesions was associated to risk factors.

Mean age was 24 years, and $33(51 \%)$ were smokers. Mean waist to hip ratio, heart weight, and cholesterol concentration $(0.84,327 \mathrm{~g}$, and $4.42 \mathrm{mmol} / \mathrm{l})$ were within $95 \%$ confidence intervals of reference values. ${ }^{3}$

Fibrous plaques were present in $17(34 \% ; 95 \%$ confidence interval $21 \%$ to $49 \%)$ men but were absent $(0$; $0 \%$ to $22 \%$ ) in women. Compared with the 33 men without plaques, the 17 men with plaques were on average 6 years older $(\mathrm{P}<0.001)$ and had significantly higher serum total cholesterol (by $0.76 \mathrm{mmol} / \mathrm{l}$ ) and very low density lipoprotein cholesterol (by 0.27 $\mathrm{mmol} / \mathrm{l}) \quad(\mathrm{P}<0.05$ for both) (figure). Measures of

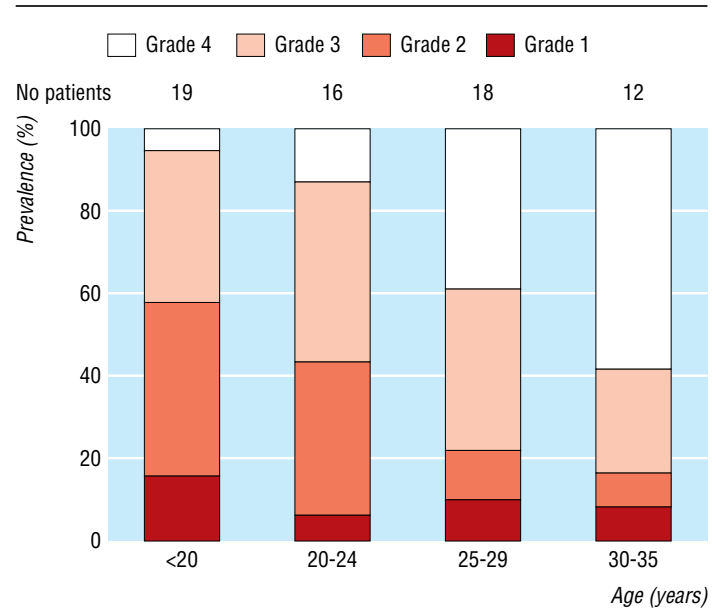

Prevalence of atherosclerotic lesion in the left coronary artery of 65 young Spanish trauma victims according to age; fibrous plaques are more likely with increasing age $\left(\chi^{2}=13.78, P=0.003\right)$; grade

1 -isolated intimal foam cells, minimal changes; grade 2 -numerous intimal foam cells often in layers, fatty streaks; grade 3-pools of extracellular lipid without a well defined core, intermediate lesions, or preatheroma; grade 4-well defined lipid cores with a luminal surface covered by normal intima, atheroma, or fibrous plaques; grade 5-lipid cores with a fibrous cap with or without calcification, fibroatheroma; grade 6-fibroatheroma with cap defects such as haemorrhage or thrombosis, complicated lesions (we did not find lesions of grades 5 or 6 )

adiposity, smoking behaviour, and the fatty acids in adipose tissue were similar in men with and without plaques.

\section{Comment}

We found unexpectedly high numbers of plaques in young Spanish men, similar to the prevalence in populations with much higher rates of coronary heart disease, ${ }^{1}$ for Barcelona, a geographical location with low incidence of myocardial infarction. ${ }^{2}$ The most advanced lesions were fibrous plaques - that is, stable atheroma-and not the vulnerable plaques that underlie acute coronary syndromes and which rupture easily. The decreasing prevalence of fatty streaks and the increasing rates of more advanced lesions with age suggests a temporal progression of lesion severity (figure). Abnormal blood lipids were associated with coronary plaques.

Morbidity and mortality from myocardial infarction are low in Spain, ${ }^{2}$ but angina is as common as in Western countries with higher rates of coronary heart disease. ${ }^{3}$ In Spain, coronary atherosclerosis evolves more slowly. Although a time lag to increased rates of coronary heart disease could be approaching its end, ${ }^{4}$ unknown protective factors might also prevent coronary plaques from becoming unstable in this population.
Institut de Medicina Legal de Catalunya, C Prim 32-40, Badalona, E-08911, Spain

Antonia Bertomeu coroner

Hospital Sant Jaume, C Sant Jaume 209-217,

Calella (Barcelona), E-08370, Spain

Olga García-Vidal pathologist

Centro Nacional de Investigaciones

Oncológicas, C

Melchor Fernández Almagro 3, Madrid, E-28029, Spain

Xavier Farré pathologist

Hospital Municipal de Badalona, Via Augusta 9-13,

Badalona, E-08911, Spain

Albert Galobart lecturer

Departamento de Farmacología, Facultad de

Farmacia,

Universitat de

Barcelona, Diagonal

643, Barcelona,

E-08028, Spain

Manuel Vázquez

professor

Juan Carlos Laguna professor

Unidad de Lípidos, Servicio de

Nutrición y

Dietética, Institut

d'Investigacions

Biomèdiques

August Pi i Sunyer,

Hospital Clínic, C

Villarroel 170,

Barcelona, E-08036,

Spain

Emilio Ros

senior lecturer

Correspondence to A Bertomeu

23217abr@comb.es

BMJ 2003;327:591-2

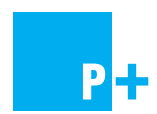

Details of the study group are on bmj.com 
We thank M Vaquero for dissecting the coronary arteries; J C Borondo for pathologic evaluations; R Llombart for collecting anatomical specimens; E Casals for supervising biochemical analyses; D Zambon for support in statistical analysis; M Guevara and $\mathrm{C}$ Bauchet for lipoprotein and thiocyanate determinations; Instituto Anatómico Forense, Barcelona; and J Marrugat for reviewing the manuscript.

Contributors: $\mathrm{AB}, \mathrm{ER}$, and $\mathrm{OGV}$ conceived and designed the study. OGV and XF processed the histological samples of the coronary arteries and scored the lesions. MV and JCL processed and interpreted measurements of fatty acids in adipose tissue. $\mathrm{AG}, \mathrm{XF}$, and ER analysed and interpreted the data. AB and ER drafted and revised the paper. AB and ER are guarantors. See bmj.com for details of the Estudio Forense de Aterosclerosis Preclínica study group.

Funding: Spanish Health Ministry, FIS 96/2006.

Competing interests: None declared.

Ethical approval: Not required.
1 McGill HC Jr, McMahan CA, Herderick EE, Malcom GT, Tracy RE, Strong JP. Origin of atherosclerosis in childhood and adolescence. Am Clin Nutr 2000;72(suppl):1307-15S.

2 Tunstall-Pedoe H, Vanuzzo D, Hobbs M, Mahonen M, Cepaitis Z, Kuulasmaa K, et al. Estimation of contribution of changes in coronary care to improving survival, event rates, and coronary heart disease mortality across the WHO MONICA Project populations. Lancet 2000;355:688700.

3 Villar Álvarez F, Banegas Banegas JR, Donado Campos JM, Rodríguez Artalejo F. Las enfermedades cardiovasculares y sus factores de riesgo en España: hechos y cifras. Informe SEA 2003 [Cardiovascular diseases and their risk factors in Spain: facts and figures: a report from the Spanish Atherosclerosis Society 2003]. Madrid: Ergon, 2003. (In Spanish.)

4 Law M, Wald N. Why heart disease mortality is low in France: the time lag explanation. BMJ 1999;318:1471-80.

5 Marrugat J, Masiá R, Elosua R, Covas MI. Cardiovascular protective factors: can they explain for differences in mortality and morbidity between the Mediterranean and the Anglo-Saxon population? Cardiovaso Risk Factors 1998;9:196-204.

(Accepted 15 July 2003)

\section{Contribution of timetabled physical education to total physical activity in primary school children: cross sectional study}

Katie M Mallam, Brad S Metcalf, Joanne Kirkby, Linda D Voss, Terence J Wilkin

Department of Endocrinology and Metabolism, Peninsula Medical School, Derriford Hospital, Plymouth PL6 8DH

Katie M Mallam paediatric research fellow

Brad S Metcalf statistician

Joanne Kirkby assistant statistician Linda D Voss senior research fellow Terence J Wilkin professor of medicine

Correspondence to: T J Wilkin

terence.wilkin@ phnt.swest.nhs.uk

BMJ 2003;327:592-3
A recent survey of children at primary schools in England found a marked decline in timetabled physical education between 1994 and 1999. ${ }^{1}$ Sport England expressed concern about the impact of competing priorities, such as numeracy and literacy, on curricular physical education and concluded that children from poorer backgrounds would be worst affected. We used accelerometers to measure the impact of timetabled physical education at school on overall physical activity in children.

\section{Participants, methods, and results}

We monitored physical activity during waking hours for seven days using accelerometers (Manufacturing Technology, Fort Walton Beach, $\mathrm{FL}^{2}$ ) in 215 children (120 boys and 95 girls aged 7.0-10.5 (mean 9.0) years) from three schools with different sporting facilities and opportunity for physical education in the curriculum. School 1, a private preparatory school with some boarding pupils, had extensive facilities and 9.0 hours a week of physical education in the curriculum. School 2, a village school awarded Activemark gold status for its focus on physical activity, offered 2.2 hours of timetabled physical education a week. School 3, an inner city school with limited sporting provision, offered 1.8 hours of physical education a week.

The accelerometer electronically measures clock time, duration and intensity of movement, and is highly reproducible. ${ }^{3}$ Compliance was defined as complete recordings over at least four school days and one day of the weekend. Parents completed questionnaires assessing their income on a six point scale. We used analysis of variance to compare means between schools. Least significant difference $\mathrm{P}$ values are quoted.

A total of $74 \%$ ( 85 boys and 74 girls) complied with their accelerometers; compliant and non-compliant children did not differ in body mass index $\left(\mathrm{kg} / \mathrm{m}^{2}\right)$ or household income. As expected, pupils in School 1 recorded the most activity in school time but this was barely twice that of pupils in Schools 2 or 3 (both $\mathrm{P}<0.001)$ despite timetabling more than four times the amount of physical education (figure). Surprisingly, total physical activity between schools was similar because children in Schools 2 and 3 did correspondingly more activity out of school than children at
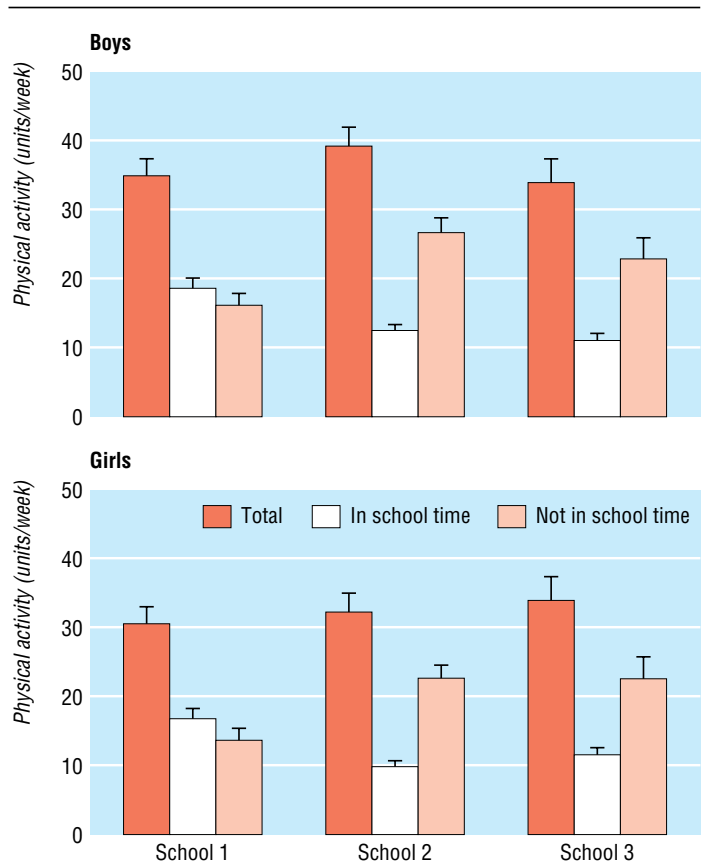

Mean physical activity done by children at three primary schools (error bars show upper limit of 95\% confidence interval) 